Mini Review

\title{
Extraction and Electrochemical Analysis of Polyphenols in Plant Samples
}

\author{
Xianrong Zhou*, Yan Zhang, Bo Jiang \\ School of Advanced Agriculture and Bioengineering, Yangtze Normal University, Chongqing, \\ 408100, P.R. China \\ *E-mail: zhouxianrong@yznu.cn
}

doi: $10.20964 / 2019.08 .83$

Received: 7 April 2019 / Accepted: 6 June 2019 / Published: 30 June 2019

\begin{abstract}
Plant polyphenols are polyphenolic secondary metabolites that widely exists in plants and are mainly found in the skin, root, leaf and fruit. Plant polyphenols are natural antioxidants and are the most powerful free radical scavengers known. Therefore, the extraction and analysis of these polyphenols has attracted considerable attention. In this review, the extraction of plant polyphenols is discussed. Then, we focus on methods for the analysis and determination of plant polyphenols with a specific focus on analysis and detection methods based on electrochemical sensing.
\end{abstract}

Keywords: Electroanalytical chemistry; Polyphenol, Plant tissue; Analytical method; Analyte

\section{FULL TEXT}

(C) 2019 The Authors. Published by ESG (www.electrochemsci.org). This article is an open access article distributed under the terms and conditions of the Creative Commons Attribution license (http://creativecommons.org/licenses/by/4.0/). 